\title{
Efeito de Idade à Castração e de Grupos Genéticos sobre o Desempenho em Confinamento e Características de Carcaça
}

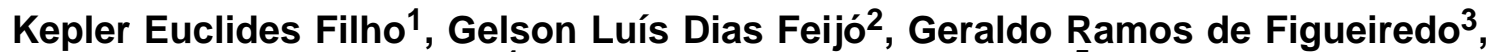 \\ Valéria Pacheco Batista Euclides ${ }^{4}$, Luiz Otávio Campos da Silva ${ }^{5}$, Viviane Queiroz Cusinato ${ }^{6}$
}

RESUMO - Foram utilizados 71 animais pertencentes a dois grupos genéticos com diferentes potenciais de crescimento, $1 / 2$ Angus $1 / 2$ Nelore (AN) e 1/2 Simental - 1/2 Nelore (SN). Esses animais, pertencentes a um projeto amplo denominado Projeto Cruzamento Embrapa 1 , foram submetidos a sete tratamentos de castração. Observou-se que os animais SN permaneceram 14 dias a mais, em confinamento, para que fossem abatidos com o mesmo grau de acabamento que os AN (131 dias versus 117 dias, respectivamente). As demais características estudadas, peso de abate, peso de carcaça fria, rendimento de carcaça e área de olho-de-lombo, não foram influenciadas pelo grupo genético e apresentaram, nessa mesma seqüência, médias iguais a $471 \mathrm{~kg}$ e $476 \mathrm{~kg}, 266 \mathrm{~kg}$ e $274 \mathrm{~kg}, 58,13 \%$ e $57,46 \%$ e $72,71 \mathrm{~cm}^{2}$ e $75,79 \mathrm{~cm}^{2}$ para AN e SN, respectivamente. As comparações entre as médias dos diferentes tratamentos foram realizadas utilizando-se seis contrastes. Verificou-se que os animais inteiros permaneceram 25 dias a mais em confinamento do que aqueles castrados no nascimento (136 dias versus 111 dias, respectivamente). No entanto, estes animais apresentaram peso médio de abate superior àqueles observados para os animais castrados no nascimento ( $515 \mathrm{~kg}$ versus $463 \mathrm{~kg}$, respectivamente). Animais castrados no nascimento permaneceram mais tempo em confinamento do que aqueles castrados na desmama ou com um ano de idade (111 dias versus 95 dias, respectivamente). Os animais confinados logo após a desmama, como era de se esperar, foram aqueles que permaneceram mais tempo em confinamento (181 dias). Por serem animais jovens, um ano mais novos que os demais, esse maior tempo em confinamento não refletiu em pesos de abate mais elevados (455 kg). O rendimento médio de carcaça, independente do grupo genético e tratamento, foi de 57,79\%.

Palavras-chave: Angus, bovinos de corte, confinamento, cruzamento, eficiência, Nelore, Simental

\section{Effect of Age at Castration and Genetic Groups on Performance and Carcass Traits}

\begin{abstract}
Seventy-one animals from two genetic groups, $1 / 2$ Angus - $1 / 2$ Nellore (AN) and $1 / 2$ Simmental - $1 / 2$ Nellore (SN) with different growth potential, which belonged to the Projeto Cruzamento Embrapa 1 were used. These groups were submitted to seven castration treatments. It was observed that the SN animals delayed 14 more days in feedlot in order to be slaughtered in the same degree of finishing as the AN (131 days versus 117 days, respectively) animals. The other evaluated traits, slaughter weight, cold carcass weight, carcass dressing, longissimus muscle area, were not affected by genetic group. The averages for these traits in this same sequence were $471 \mathrm{~kg}$ and $476 \mathrm{~kg}, 266 \mathrm{~kg}$ and $274 \mathrm{~kg}, 58.13 \%$ and $57.46 \%$ and $72.71 \mathrm{~cm}^{2}$ and $75.79 \mathrm{~cm}^{2}$ for AN and SN animals, respectively. The comparisons among treatment means were carried out through six different contrasts. It was observed that young bulls delayed under feedlot confinement 25 more days than those castrated at birth (136 days versus 111 days, respectively). However, these animals showed heavier slaughter weight than those castrated at birth ( $515 \mathrm{~kg}$ versus $463 \mathrm{~kg}$, respectively). Animals castrated at birth stayed longer in feedlot than those castrated at weaning or castrated as yearling (111 days versus 95 days, respectively). Animals feedlot confined just after weaning, as it should be expected, were those that delayed longer under feedlot confinement (181 days). Since these animals were one year younger than the other animals, the longer time required for them to attain the end point did not result in heavier slaughter weights $(455 \mathrm{~kg})$. The average carcass dressing independent on genetic group and treatment was $57.79 \%$.
\end{abstract}

Key Words: Angus, beef cattle, crossbred, efficiency, feedlot, Nellore, Simmental

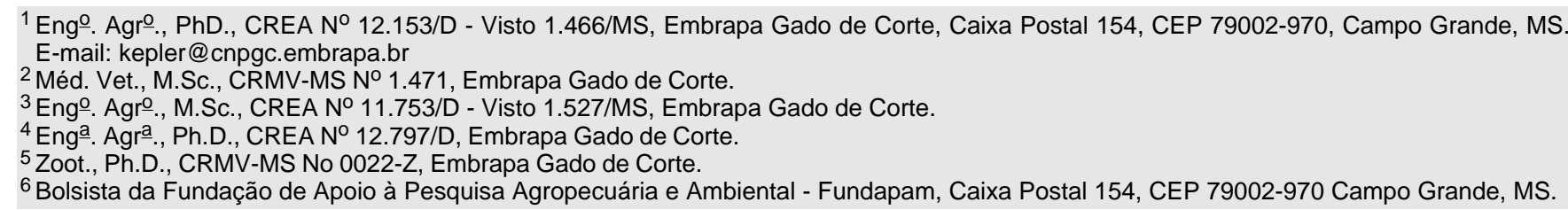




\section{Introdução}

A castração desde há muito tempo tem se constituído em uma prática comum na pecuária de corte, a qual tem como principais vantagens a maior facilidade de manejo, uma vez que torna os animais mais dóceis e, a melhoria da qualidade da carcaça, o que contribui para sua maior aceitação no mercado, especialmente no tocante à indústria frigorífica. Nesse aspecto, a principal contribuição da castração tem sido resultante de seu efeito sobre a cobertura de gordura necessária para a proteção da carcaça contra o frio durante o processo de armazenamento.

No Brasil, a prática de castração tem sido realizada, nos sistemas de produção tradicionais, aproximadamente, aos 20 meses de idade. Todavia, os sistemas de produção de bovinos de corte vêm sofrendo alterações e se intensificando. Nesse novo cenário, a idade média de abate tem diminuído sensivelmente, principalmente, pelo incremento do número de animais classificados na categoria de novilho precoce que é constituída, na maioria dos casos, por indivíduos com idades variando entre 18 e 36 meses. Mais recentemente, nota-se o crescimento de novo segmento, que visa à produção de animais para abate aos 12-14 meses de idade, os chamados novilhos superprecoces.

Associadas a essas mudanças, outras vêm se processando e, com elas, vem crescendo a participação dos cruzamentos e do confinamento na produção de carne bovina no país.

Nessa nova perspectiva, há necessidade de se redefinir a melhor idade de castração, uma vez que, em muitos casos, grande número de animais tem sido abatidos entre 20 e 24 meses de idade. Os cruzamentos vêm se consolidando e devem, segundo EUCLIDES FILHO $(1997,1998)$, se constituir, cada vez mais, em uma alternativa, bioeconomicamente, importante de produção de carne bovina no Brasil. No entanto, é importante ressaltar que raças com diferentes potenciais para crescimento apresentam também variações nas taxas de maturidade e, conseqüentemente, na velocidade de deposição de gordura (BRUNGARDT, 1973, citado por TAYLOR, 1994).

Dessa forma, torna-se fundamental, tanto a determinação da melhor idade à castração quanto a compreensão de seus efeitos e/ou de suas interações com grupos genéticos, especialmente, quando esses apresentam diferentes taxas de deposição de gordura, ou seja, distintas taxas de maturação. Assim, este trabalho foi conduzido com o objetivo de avaliar o efeito de diferentes idades à castração, e de suas inter-relações com grupo genético, sobre o peso de abate e algumas características de carcaça de animais representando dois tamanhos adultos e duas taxas de maturidade.

\section{Material e Métodos}

Foramutilizados 71 animais de dois grupos genéticos, sendo 37 1 1/2 Angus - 1/2 Nelore e 34 1/2 Simental - 1/2 Nelore, representando genótipos precoces e tardios, respectivamente; distribuídos em sete tratamentos: T1- animais inteiros, I; T2 - animais inteiros submetidos ao creep feeding, I + CRF; T3 - animais castrados ao nascimento, CN; T4 - animais castrados ao nascimento submetidos ao creep feeding, $\mathrm{CN}+$ CRF; T5 - animais castrados à desmama, CD; T6 - animais castrados a um ano de idade, C12; e T7 - animais inteiros confinados após a desmama, I + CONF. Esses animais faziam parte de um projeto amplo, que se encontra em andamento e visa à avaliação da eficiência de produção de carne bovina em sistemas de produção envolvendo animais de médio e grande porte (Projeto Cruzamento Embrapa 1), e foram, à exceção daqueles do tratamento I + CONF, desmamados no mês de maio de 1997 , após terem sido criados com as mães em pastagens de Brachiaria decumbens. Os animais do tratamento I + CONF foram desmamados em maio de 1998 e foram confinados no mesmo ano. Os touros Simental nesse projeto são de peso adulto elevado (acima de $1100 \mathrm{~kg}$ de peso vivo), enquanto os touros Angus são de tamanho médio (abaixo de $1000 \mathrm{~kg}$ de peso vivo).

Aos 90 dias de idade, aproximadamente, 14 animais começaram a receber uma ração suplementar em cochos privativos ao qual tiveram acesso até a desmama (creep feeding). Essa ração foi constituída por uma mistura de $24,49 \%$ de farelo de soja e $73,48 \%$ de grão de milho moído, $1,96 \%$ de uréia e $0,07 \%$ de Rumensin ${ }^{\circledR}$, com base na matéria seca, e fornecida na proporção de, aproximadamente, $0,5 \%$ do peso vivo. Após a desmama, todos animais, incluindo aqueles que não receberam suplementação durante o aleitamento, passaram a receber uma suplementação alimentar com a mesma ração utilizada no creep feeding. Nesse caso, o fornecimento foi feito na base de $1 \%$ do peso vivo dos animais. Em ambos os casos, creep feeding ou suplementação após desmama, as quantidades de ração fornecida foram ajustadas a cada 28 dias com base nos pesos vivos obtidos mensalmente. Em julho, todos animais 
Rev. bras. zootec.

foram colocados em piquetes coletivos providos de bebedouros e cochos para fornecimento da suplementação mineral, além dos cochos para distribuição da ração.

Os animais foram agrupados por tratamento e grupo genético e permaneceram em alimentação até o momento do abate. Os primeiros 14 dias foram considerados como período de adaptação. O ponto de avaliação utilizado foi grau de acabamento, que era determinado por avaliação visual, sendo os animais abatidos, quando atingiam $5 \mathrm{~mm}$ de espessura de gordura de cobertura. Para acompanhamento do desempenho, os animais foram pesados a cada 28 dias com jejum prévio de, aproximadamente, 16 horas. Este jejum também foi observado antes da obtenção do peso de abate. Para o confinamento, foram utilizadas duas rações formuladas com base no peso inicial, no peso adulto dos grupos genéticos e na idade dos animais. Assim, os animais confinados após a desmama, tratamento 7 , receberam uma ração contendo, aproximadamente, $71 \%$ de NDT e $16 \%$ de $\mathrm{PB}$, enquanto que para os animais dos demais tratamentos, a ração continha $75 \%$ de NDT e $12 \%$ de PB. A primeira ração era composta por $41 \%$ de grão de milho moído, $56 \%$ de farelo de soja e $3 \%$ de calcário, a segunda continha $73,3 \%$ de grão de milho moído, $19 \%$ de farelo de soja, $4,5 \%$ de uréia, $0,5 \%$ de flor de enxofre e 2,7 de calcário. Para cada $100 \mathrm{~kg}$ de concentrado, foram adicionados 20 e $40 \mathrm{~g}$ de Rumensin ${ }^{\circledR}$ nas rações $\mathrm{A}$ e $\mathrm{B}$, respectivamente.

Os dados foram analisados utilizando-se um modelo matemático contendo os efeitos fixos de grupo genético, tratamento e a interação simples entre esses. Além destes, espessura de gordura (EG) foi utilizada como covariável. Esse modelo foi utilizado para analisar peso ao abate (PA), peso de carcaça fria (PCF), dias em confinamento (DC), rendimento de carcaça (RC) e área de olho de lombo (AOL). Os seguintes contrastes foram utilizados para teste dos tratamentos: $\mathrm{C}_{1}$ ) tratamento I versus tratamento $\mathrm{I}+\mathrm{CRF} ; \mathrm{C}_{2}$ ) tratamento $\mathrm{CN}$ versus tratamento $\mathrm{CN}+\mathrm{CRF} ; \mathrm{C}_{3}$ ) média dos tratamentos I e I + CRF versus média dos tratamentos $\mathrm{CN}$ e $\mathrm{CN}+\mathrm{CRF} ; \mathrm{C}_{4}$ ) tratamento $\mathrm{CD}$ versus tratamento $\mathrm{C} 12 ; \mathrm{C}_{5}$ ) tratamento $\mathrm{I}+\mathrm{CONF}$ versus média de todos os demais tratamentos e; $\mathrm{C}_{6}$ ) média dos tratamentos $\mathrm{CN}$ e $\mathrm{CN}+\mathrm{CRF}$ versus média dos tratamentos $\mathrm{CD}$ e $\mathrm{C} 12$.

\section{Resultados e Discussão}

Dias em confinamento foi a única característica influenciada $(\mathrm{P}<0,05)$ pelo grupo genético, enquanto o tratamento de castração influenciou, significativamente $(\mathrm{P}<0,01)$, as variáveis $\mathrm{PA}$, DC e AOL (Tabelas 1 e 2). Como não houve efeito da interação GG x T (P>0,05), as médias de quadrados mínimos, para as características avaliadas, foram apresentadas de acordo com o grupo genético e o tratamento de castração e encontram-se nas Tabelas 3, 4 e 5.

Os animais $\mathrm{SN}$ permaneceram, em média, 14 dias a mais em confinamento (131 dias versus 117 dias, para $\mathrm{SN}$ e AN, respectivamente), para que fossem abatidos com o mesmo grau de acabamento de car-

Tabela 1 - Resumo das análises de variância para peso de abate (PA) e dias em confinamento (DC) Table 1 - Summary of the analyses of variance for slaughter weight and days in feedlot

\begin{tabular}{|c|c|c|c|}
\hline \multirow[t]{2}{*}{$\begin{array}{l}\text { Fonte de variação } \\
\text { Source of variation }\end{array}$} & \multirow[t]{2}{*}{$\begin{array}{l}\mathrm{G} \\
D F\end{array}$} & \multicolumn{2}{|c|}{$\begin{array}{l}\text { Quadrados médios } \\
\text { Mean squares }\end{array}$} \\
\hline & & $\begin{array}{l}\text { Peso de abate } \\
\text { Slaughterweight }\end{array}$ & $\begin{array}{c}\text { Dias em confinamento } \\
\text { Days in feedlot }\end{array}$ \\
\hline $\begin{array}{l}\text { Grupo genético }(\mathrm{GG}) \\
\text { Genetic group }(G G)\end{array}$ & 1 & 312,49 & $2442,20^{*}$ \\
\hline $\begin{array}{l}\text { Tratamento }(\mathrm{T}) \\
\text { Treatment }(T)\end{array}$ & 6 & $5353,22^{* *}$ & $8422,36^{* *}$ \\
\hline $\begin{array}{l}\mathrm{GG} * \mathrm{~T} \\
G G * T\end{array}$ & 6 & 702,81 & 617,91 \\
\hline $\begin{array}{l}\text { Espessura de gordura } \\
\text { Fat thickness }\end{array}$ & 1 & $4.867,04$ & $1.365,41$ \\
\hline $\begin{array}{l}\text { Resíduo } \\
\text { Error }\end{array}$ & 68 & $1.204,18$ & 565,30 \\
\hline
\end{tabular}


Tabela 2 - Resumo das análises de variância para características de carcaça Table 2 - Summary of analyses of variance for carcass traits

\begin{tabular}{|c|c|c|c|c|}
\hline \multirow[t]{2}{*}{$\begin{array}{l}\text { Fonte de variação } \\
\text { Source of variation }\end{array}$} & \multirow[t]{2}{*}{$\begin{array}{l}\text { GL } \\
D F\end{array}$} & \multicolumn{3}{|c|}{$\begin{array}{l}\text { Quadrados médios } \\
\text { Mean squares }\end{array}$} \\
\hline & & $\begin{array}{l}\mathrm{PCF} \\
C C W\end{array}$ & $\begin{array}{l}\mathrm{RC} \\
\mathrm{DP}\end{array}$ & $\begin{array}{l}\mathrm{AOL} \\
R E A\end{array}$ \\
\hline $\begin{array}{l}\text { Grupo genético }(\mathrm{GG}) \\
\text { Genetic group }(G G)\end{array}$ & 1 & 823,51 & 5,82 & 122,28 \\
\hline $\begin{array}{l}\text { Tratamento }(\mathrm{T}) \\
\text { Treatment }(T)\end{array}$ & 6 & 1612,51 & 3,83 & $173,01^{* *}$ \\
\hline $\begin{array}{l}\mathrm{GG} * \mathrm{~T} \\
G G * T\end{array}$ & 6 & 400,06 & 0,37 & 19,47 \\
\hline $\begin{array}{l}\text { Espessura de gordura } \\
\text { Fat thickness }\end{array}$ & 1 & 938,15 & 0,20 & 3,04 \\
\hline $\begin{array}{l}\text { Resíduo } \\
\text { Error }\end{array}$ & 68 & 793,92 & 2,02 & 43,99 \\
\hline
\end{tabular}

Tabela 3 - Médias de quadrados mínimos para características de carcaça, de acordo com o grupo genético

Table 3 - Least square means for carcass traits, according to genetic group

\begin{tabular}{|c|c|c|}
\hline \multirow[t]{2}{*}{$\begin{array}{l}\text { Característica } \\
\text { Trait }\end{array}$} & \multicolumn{2}{|c|}{$\begin{array}{l}\text { Grupo genético } \\
\text { Genetic group }\end{array}$} \\
\hline & AN & SN \\
\hline $\begin{array}{l}\text { Peso ao abate, } \mathrm{kg} \\
\text { Slaughter weight, } \mathrm{kg}\end{array}$ & 471 & 476 \\
\hline $\begin{array}{l}\text { Peso de carcaça fria, } \mathrm{kg} \\
\text { Cold carcass weight, } \mathrm{kg}\end{array}$ & 266 & 274 \\
\hline $\begin{array}{l}\text { Dias em confinamento } \\
\text { Days in feedlot }\end{array}$ & 117 & 131 \\
\hline $\begin{array}{l}\text { Rendimento de carcaça, \% } \\
\text { Dressing percentage, \% }\end{array}$ & 58,13 & 57,46 \\
\hline $\begin{array}{l}\text { Área de olho de lombo, } \mathrm{cm}^{2} \\
\text { Longissimus muscle area, } \mathrm{cm}^{2}\end{array}$ & 72,71 & 75,79 \\
\hline
\end{tabular}

caça alcançado pelos animais AN. A espessura média de gordura foi de $4,3 \mathrm{~mm}$. Esse desempenho inferior do grupo $\mathrm{SN}$, possivelmente, é resultado de maior exigência de mantença apresentada por esses animais em relação aos AN. Isso encontra respaldo no fato de não ter havido diferença nos pesos de abate entre esses dois grupos genéticos $(\mathrm{P}>0,61)$, que foram, aproximadamente, 471 e $476 \mathrm{~kg}$ para AN e SN, respectivamente. Essa possível diferença nos
Tabela 4 - Médias de quadrados mínimos para peso de abate e peso de carcaça fria, de acordo com o tratamento de castração

Table 4 - Least square means for slaughter weight and cold carcass weight, according to castration treatment

\begin{tabular}{lcc}
\hline $\begin{array}{l}\text { Tratamento } \\
\text { Treatment }\end{array}$ & $\begin{array}{c}\text { Peso de } \\
\text { Abate, kg } \\
\text { Slaughter } \\
\text { weight, } k g\end{array}$ & $\begin{array}{c}\text { Peso de Carcaça } \\
\text { Fria, kg } \\
\text { Cold carcass } \\
\text { weight, } k g\end{array}$ \\
\hline I & 514 & 298 \\
I + CRF & 517 & 293 \\
CN & 465 & 257 \\
CN + CRF & 462 & 266 \\
CD & 463 & 257 \\
C12 & 440 & 262 \\
I+CONF & 455 & 260 \\
\hline
\end{tabular}

requerimentos de mantença, observada para os dois grupos genéticos estudados, estão de acordo com as recomendações do NATIONAL RESEARCH COUNCIL - NRC (1996).

As demais características de carcaça avaliadas apresentaram, respectivamente, as seguintes médias: 266 e $274 \mathrm{~kg}$ para PCF; 58,13 e 57,46\% para RC; e 72,71 e $75,79 \mathrm{~cm}^{2}$ para AOL, para AN e SN, respectivamente. A idade à castração influenciou significa- 
tivamente $(\mathrm{P}<0,01)$ o número de dias que os animais permaneceram em confinamento até atingirem o ponto de abate pré-estabelecido. Pelos contrastes estudados, verificou-se que os animais inteiros (tratamentos $\mathrm{Ie} \mathrm{I}+\mathrm{CF}$ ) permaneceram mais tempo em confinamento do que os castrados ao nascimento (136 dias versus 111 dias, respectivamente).

Esta necessidade de mais tempo para alcançar determinado grau de acabamento se constitui em um aspecto importante, mesmo considerando-se o fato de que, normalmente, os animais inteiros apresentam maior ganho de peso e maior peso final. De fato, no caso presente, estes animais apresentaram peso médio de abate superior àqueles observados para os animais castrados no nascimento $(515 \mathrm{~kg}$ versus $463 \mathrm{~kg}$, respectivamente). Essa diferença é conseqüência direta do ponto de avaliação dos animais adotado no trabalho, ou seja, grau de acabamento. Como os animais inteiros iniciam o processo de deposição de gordura mais tarde, eles normalmente são abatidos com pesos mais elevados. Resultados apresentando tendências semelhantes foram obtidos por RESTLE e VAZ (1997) e MOLETTA e PEROTTO (1998).

Quanto ao efeito da suplementação alimentar dos bezerros durante o aleitamento, não houve diferença entre o número de dias em confinamento para os animais castrados no nascimento, recebendo ou não creep feeding. Esses resultados estão, aparentemente, em discordância com outros que sugerem desempenho superior para animais que recebem alimentação concentrada nesse período (PACOLA et al., 1977; PACOLA et al., 1991). No entanto, é possível que isso se deva às ótimas condições em que se encontravam as pastagens e à excelente condição corporal das vacas. O tempo médio necessário para que animais castrados no nascimento atingissem o ponto de avaliação pré-definido foi de, aproximadamente, 111 dias. Esse tempo em confinamento foi superior $(\mathrm{P}<0,05)$, em 16 dias, ao tempo médio gasto pelos animais dos tratamentos $\mathrm{CD}$ e $\mathrm{C} 12$ que foi, aproximadamente, 95 dias.

As castrações na desmama, ou com um ano de idade, por outro lado, não resultaram em diferenças nos tempos de confinamento (97 versus 94 dias, respectivamente). Dessa forma, recomenda-se que, no caso de se proceder à castração, que essa seja feita na desmama, considerando-se a precocidade reprodutiva desses animais "meio-sangue" e a maior facilidade de manejo, além da provável redução do efeito do estresse.

Os animais superprecoces, tratamento $\mathrm{I}+\mathrm{CF}$, foram aqueles que necessitaram de mais tempo em confinamento. Esses animais permaneceram, em média, no confinamento, até atingirem o ponto de abate, por 181 dias.

Para as características de carcaça estudadas, a idade de castração influenciou $(\mathrm{P}<0,05)$ o peso de abate e a área de olho de lombo. Para o peso de abate, somente foi significativa a diferença representada pelo contraste $\mathrm{C}_{3}$, que eqüivaleu a $52 \mathrm{~kg}(515 \mathrm{~kg}$ versus $463 \mathrm{~kg}$, para média dos tratamentos I e I + CRF e média dos tratamentos $\mathrm{CN}$ e $\mathrm{CN}+\mathrm{CRF}$, respectivamente).

No tocante à $\mathrm{AOL}$, foram observadas diferenças entre os valores obtidos pelos animais inteiros que não receberam creep feeding (tratamento I) e aqueles que receberam tratamento $\mathrm{I}+\mathrm{CRF}\left(84,14 \mathrm{~cm}^{2}\right.$ versus $73,34 \mathrm{~cm}^{2}$, respectivamente) e entre a média desses dois tratamentos comparada com aquela dos animais castrados ao nascimento (tratamentos $\mathrm{CN}$ e $\mathrm{CN}+$ CRF) $\left(78,74 \mathrm{~cm}^{2}\right.$ versus $\left.72,05 \mathrm{~cm}^{2}\right)$. Enquanto esse último resultado pode ser explicado pela maior carca-

Tabela 5 - Médias de quadrados mínimos para dias em confinamento (dias), rendimento de carcaça (\%) e área de olho-delombo $\left(\mathrm{cm}^{2}\right)$, de acordo com o tratamento de castração

Table 5 - Least square means for days in feedlot (days), dressing percentage (\%) and longssimus muscle area (cm²), according to castration treatment

\begin{tabular}{lccc}
\hline $\begin{array}{l}\text { Tratamento } \\
\text { Treatment }\end{array}$ & $\begin{array}{c}\text { Dias em confinamento } \\
\text { Days in feedlot }\end{array}$ & $\begin{array}{c}\text { Rendimento de carcaça, \% } \\
\text { Dressing percentage, } \%\end{array}$ & $\begin{array}{c}\text { Área de olho de lombo, } \mathrm{cm}^{2} \\
\text { Longissimus muscle area, } \mathrm{cm}^{2}\end{array}$ \\
\hline I & 145 & 59,78 & 84,14 \\
$\mathrm{I}+\mathrm{CRF}$ & 127 & 57,54 & 73,34 \\
$\mathrm{CN}$ & 110 & 57,59 & 70,27 \\
$\mathrm{CN}+\mathrm{CRF}$ & 113 & 57,61 & 73,89 \\
$\mathrm{CD}$ & 97 & 56,99 & 69,66 \\
$\mathrm{C} 12$ & 94 & 57,07 & 69,56 \\
$\mathrm{I}+\mathrm{CONF}$ & 181 & 57,98 & 78,88 \\
\hline
\end{tabular}


ça apresentada pelos animais inteiros dos tratamentos I e I + CRF, o primeiro não encontra respaldo nesse argumento. Possivelmente, tais diferenças sejam, simplesmente, reflexos das tendências observadas para os pesos de abate e pesos de carcaça fria desses animais.

No entanto, é importante ressaltar o desempenho dos animais inteiros confinados após a desmama. Esses animais não apresentaram diferença em relação à média dos demais tratamentos, para nenhuma das características de carcaça analisadas $(\mathrm{P}>0,05)$, exceto para área de olho de lombo $(\mathrm{P}<0,05)$, que foi superior à média dos demais tratamentos $\left(78,88 \mathrm{~cm}^{2}\right.$ versus $73,48 \mathrm{~cm}^{2}$, respectivamente). Outros autores, como RESTLE e VAZ (1997), têm obtido resultados que indicam não haver diferenças importantes na carcaça de animais inteiros submetidos, ainda jovens, a altos níveis nutricionais e animais castrados. Esses resultados sugerem que tais animais, além de apresentarem bom desempenho ponderal, alcançam cobertura de gordura suficiente para garantir boa proteção da carcaça contra o frio no armazenamento e garantir carne de ótima qualidade com aparência desejável.

Quanto ao rendimento de carcaça, vale ressaltar que não houve diferença entre os rendimentos médios de carcaça dos animais inteiros e castrados no nascimento $(58,66 \%$ versus $57,60 \%$, respectivamente) e entre a média de todos os tratamentos e aquela do tratamento I + CONF $(57,76 \%$ versus $57,98 \%$, respectivamente $)$. Isso é importante, especialmente, pelo fato de indicar a possibilidade de abater animais superprecoces com carcaças de qualidade competitiva. Rendimentos semelhantes para animais inteiros e castrados foram também observados por FIELD (1971) e MORGAN et al. (1993).

\section{Conclusões}

Animais inteiros, excetuando-se os superprecoces, para alcançarem o grau de acabamento desejado, $5 \mathrm{~mm}$, necessitam ser abatidos com pesos mais elevados que animais castrados.

Animais inteiros, confinados logo após a desmama, apresentam desempenho adequado e carcaça de qualidade comparável aos animais confinados, aproximadamente, aos 20 meses de idade.

Nas condições do presente trabalho, o fornecimento de ração concentrada para bezerros, durante o período de aleitamento (creep feeding), não resultou em nenhum benefício adicional.

A necessidade de permanecer mais tempo em confinamento, para atingir o grau de acabamento de $5 \mathrm{~mm}$ de gordura, pode comprometer a eficiência econômica de grupos genéticos de maior peso adulto. Esse resultado sugere a necessidade de se proceder a avaliações econômicas da terminação de animais de diferentes tamanhos adultos em confinamento.

\section{Referências Bibliográficas}

EUCLIDES FILHO, K. 1997. A pecuária de corte no Brasil: Novos horizontes, novos desafios. Campo Grande: EMBRAPA-CNPGC. 28p. (EMBRAPA-CNPGC. Documentos, 69).

EUCLIDES FILHO, K. O melhoramento genético de bovino de corte e suas inter-relações com demandas, cadeia produtiva e sistemas de produção In: SIMPÓSIO NACIONAL DA SOCIEDADE BRASILEIRA DE MELHORAMENTO ANIMAL, 2, 1998, Uberaba. Anais...Viçosa: UFV, 1998. p.207-212.

FIELD, R.A. 1971. Effect of castration on meat quality and quantity. J. Anim. Sci., 32(5):849-856.

MOLETTA, J.L., PEROTTO, D. Desempenho e características de carcaça de novilhos inteiros ou castrados ao entrar para o confinamento. In: REUNIÃO DA SOCIEDADE BRASILEIRA DE ZOOTECNIA, 35, 1998, Botucatu. Anais... Botucatu: SBZ, 1998. p.671-673.

MORGAN, J.B., WHEELER, T.L., KOOHMARAIE, M. et al. 1993. Effect of castration on myofibrillar protein turnover, endogenous proteinase activities, and muscle growth in bovine skeletal muscle. J. Anim. Sci., 71(2):408-414.

NATIONAL RESEARCH COUNCIL - NRC. 1996. Subcommittee on beef cattle nutrition (Washigton, USA). Nutrient requirements of beef cattle. 7.ed. Washington, D.C.: National Academy Press. 242p.

PACOLA, L.J., NASCIMENTO, J., MOREIRA, H.A. 1977. Alimentação suplementar de bezerros zebus: influência sobre a idade dos machos ao abate e das fêmeas à primeira cobrição. Bol. Ind. Anim., 34(2):177-201.

PACOLA, L.J., RAZOOK, A.G., BONILHA NETO, L.M. et al. 1991. Influência da suplementação em cocho privativo sobre o desempenho pós-desmama de bezerros Nelore. Bol. Ind. Anim., 48(1):13-18.

RESTLE, J., VAZ, F.N. 1997. Aspectos quantitativos da carcaça de machos Hereford, inteiros e castrados, abatidos aos quatorze meses. Pesq. Agropec. Bras., 32(10):1091-1095.

TAYLOR, R.E. 1994. Beefproduction and management decisions. 2.ed. New Jersey: Prentice Hall. 660p.

Recebido em: 07/04/00 Aceito em: 10/08/00 